\title{
Unscented Kalman Filtering for Hybrid Estimation of Spacecraft Attitude Dynamics and Rate Sensor Alignment
}

\author{
Hyun-Sam Myung1, Ki-Kyuk Yong² and Hyochoong Bang ${ }^{1}$ \\ ${ }^{1}$ Korea Advanced Institute of Science and Technology, \\ ${ }^{2}$ Korea Aerospace Research Institute, \\ Republic of Korea
}

\section{Introduction}

Requirements of highly precise pointing performance have been imposed on recently developed spacecrafts for a variety of missions. The stringent requirements have called on on-orbit estimation of spacecraft dynamics parameters and calibration of on-board sensors as indispensible practices.

Consequently, on-orbit estimation of the mass moment of inertia of spacecraft has been a major issue mostly due to the changes by solar panel deployment and a large portion of fuel consumption (Creamer et al., 1996; Ahmed et al., 1998; Bordany et al., 2000; VanDyke et al., 2004; Myung et al., 2007; Myung \& Bang, 2008; Sekhavat et al., 2009).

As for measurement sensors, on-board calibration of alignment and bias errors of attitude and rate sensors is one of the main concerns of attitude sensor calibration researches (Pittelkau, 2001 \& 2002, Lai et al., 2003). Pittelkau (2002) proposed an attitude estimator based on the Kalman filter (Kalman, 1960), in which spacecraft attitude quaternion, rate sensor misalignment and bias, and star tracker misalignments are taken into consideration as states, whereas the body rate is dealt as a synthesized signal by the estimates. Lai at al. (2003) derived a method for alignment estimation of attitude and rate sensors based on the unscented Kalman filter (UKF) (Julier and Uhlmann, 1997). Ma and Jiang (2005) presented spacecraft attitude estimation and calibration based only magnetometer measurements using an UKF.

An interesting point is that we need predesigned 3-axis excitation manoeuvres of spacecraft for both dynamics parameter estimation and sensor calibration. Therefore, this study is motivated to merge above estimation and calibration processes into a single filtering problem. It is noteworthy that poor information of moments of inertia is to be treated as a system uncertainty while the rate sensor model errors are to be incorporated into the measurement process.

As a filtering algorithm, this study employs a UKF. Extended Kalman filters (EKFs) have been successfully applied to the nonlinear attitude estimation problem (Crassidis et al., 2007). Hybrid estimation using the EKF has been reported by Myung at al. (2007). However, the EKF estimates using the first order linearization, which may lead to instability of the filter (ValDyke et al., 2004). The UKF approximates the nonlinear model to the second order by spreading points 1 sigma apart from the a priori mean. Performing nonlinear 
transformation of sigma points produces the posterior mean and covariance. Despite the computational burden of the UKF, extension of convergence region and numerical stability greatly outperform the EKF.

Parameter estimation by a dual UKF was proposed by VanDyke et al. (2004). Since UKF has more computational burden compared to EKF, a numerically efficient UKF was also developed for state and parameter estimation (van der Merwe \& Wan, 2001).

In this paper, the UKF is applied to simultaneous spacecraft dynamics estimation and rate sensor alignment calibration using star tracker measurements. The spacecraft attitude and the body angular velocity are the state vectors. Estimation parameters are the six components of moment of inertia, and the bias, scale factor errors and misalignments of a rate sensor. Numerical simulations compare the results to those using the EKF.

\section{Equation of motion of spacecraft}

\subsection{Attitude representation}

Spacecraft attitude parameter is the unit quaternion defined by

$$
\begin{aligned}
\mathrm{q} & =\left[\begin{array}{lll}
\mathbf{n}^{\mathrm{T}} \sin \left(\frac{\phi}{2}\right) & \cos \left(\frac{\phi}{2}\right)
\end{array}\right]^{\mathrm{T}} \\
& =\left[\begin{array}{llll}
\mathrm{q}_{1} & \mathrm{q}_{2} & \mathrm{q}_{3} & \mathrm{q}_{4}
\end{array}\right]^{\mathrm{T}} \\
& =\left[\begin{array}{lll}
\mathrm{q}_{13} & \mathrm{q}_{4}
\end{array}\right]^{\mathrm{T}}
\end{aligned}
$$

where $\mathbf{n}$ is the Euler axis and $\phi$ is the Euler angle. $q_{13}$ is the vector part and $q_{4}$ is the scalar part in quaternion representation. Quaternion multiplication represents successive rotation (Wertz, 1978)

$$
\begin{aligned}
\mathrm{q}^{\prime \prime} & =\mathrm{q}^{\prime} \otimes \mathrm{q} \\
& =\left[\begin{array}{rrrr}
\mathrm{q}_{4}^{\prime} & \mathrm{q}_{3}^{\prime} & -\mathrm{q}_{2}^{\prime} & \mathrm{q}_{1}^{\prime} \\
-\mathrm{q}_{3}^{\prime} & \mathrm{q}_{4}^{\prime} & \mathrm{q}_{1}^{\prime} & \mathrm{q}_{2}^{\prime} \\
\mathrm{q}_{2}^{\prime} & -\mathrm{q}_{1}^{\prime} & \mathrm{q}_{4}^{\prime} & \mathrm{q}_{3}^{\prime} \\
-\mathrm{q}_{1}^{\prime} & -\mathrm{q}_{2}^{\prime} & -\mathrm{q}_{3}^{\prime} & \mathrm{q}_{4}^{\prime}
\end{array}\right]\left[\begin{array}{l}
\mathrm{q}_{1} \\
\mathrm{q}_{2} \\
\mathrm{q}_{3} \\
\mathrm{q}_{4}
\end{array}\right]
\end{aligned}
$$

And inverse of quaternion

$$
\mathrm{q}^{-1}=\left[\begin{array}{llll}
-\mathrm{q}_{1} & -\mathrm{q}_{2} & -\mathrm{q}_{3} & \mathrm{q}_{4}
\end{array}\right]^{\mathrm{T}}
$$

implies the opposite rotation of q. By combining Eq. (2) and (3) residual rotation of q" with respect to $q^{\prime}$, or error quaternion $\delta q$, is obtained such as

$$
\delta \mathrm{q}=\mathrm{q}^{\prime \prime} \otimes\left(\mathrm{q}^{\prime}\right)^{-1}
$$

\subsection{Spacecraft attitude equation of motion}

The equation of motion of spacecraft is given as

$$
\mathrm{J} \dot{\omega}+\omega \times \mathrm{J} \omega=\mathrm{u}
$$


where $\omega \in R^{3}$ is the body angular velocity, $\mathrm{J}$ is the mass moment of inertia matrix, and $\mathrm{u} \in R^{3}$ is the external control input torque. The attitude kinematics is expressed by attitude quaternion such as (Crassidis et al., 1997)

$$
\dot{\mathrm{q}}=\frac{1}{2} \Omega(\omega) \mathrm{q}=\frac{1}{2} \Xi(\mathrm{q}) \omega
$$

where

$$
\Omega(\omega) \equiv\left[\begin{array}{c:c}
-[\omega \times] & \omega \\
\hdashline-\omega^{\mathrm{T}} & 0
\end{array}\right], \Xi(\mathrm{q}) \equiv\left[\begin{array}{c}
\mathrm{q}_{4} \mathrm{I}_{3}+\left[\mathrm{q}_{13} \times\right] \\
\hdashline-\mathrm{q}_{13}^{\mathrm{T}}
\end{array}\right]
$$

Due to the unity constraint on the attitude quaternion, only the vector component is utilized as states, and $\mathrm{q}_{4}$ is calculated from the constraint. Choosing the body angular rate as one of the states, we rewrite Eq. (5) as

$$
\dot{\omega}=-\mathrm{J}^{-1} \omega \times \mathrm{J} \omega+\mathrm{J}^{-1} \mathrm{u}
$$

The six components of the moment of inertia are defined as

$$
\mathrm{J}=\left[\begin{array}{lll}
\mathrm{J}_{11} & \mathrm{~J}_{12} & \mathrm{~J}_{13} \\
\mathrm{~J}_{12} & \mathrm{~J}_{22} & \mathrm{~J}_{23} \\
\mathrm{~J}_{13} & \mathrm{~J}_{23} & \mathrm{~J}_{33}
\end{array}\right]
$$

In the form of vector notation, we define

$$
\mathrm{p}=\left[\begin{array}{llllll}
\mathrm{J}_{11} & \mathrm{~J}_{22} & \mathrm{~J}_{33} & \mathrm{~J}_{12} & \mathrm{~J}_{13} & \mathrm{~J}_{23}
\end{array}\right]^{\mathrm{T}}
$$

\subsection{Measurement model}

The body angular velocity measurement equation at time $t=t_{k}$ is expressed as

$$
\tilde{\omega}_{\mathrm{k}}=(\mathrm{I}+\mathrm{M}) \omega_{\mathrm{k}}+\mathrm{b}+\mathrm{v}_{\omega \mathrm{k}}
$$

where $\omega$ is the true body angular velocity, $\tilde{\omega}$ is the angular velocity measurement vector, $\mathrm{M}$ is a matrix combined by the scale factor errors and the misalignments such as

$$
\mathrm{M}=\left[\begin{array}{lll}
\lambda_{1} & \delta_{12} & \delta_{13} \\
\delta_{21} & \lambda_{2} & \delta_{23} \\
\delta_{31} & \delta_{32} & \lambda_{3}
\end{array}\right]
$$

where $\mathrm{b} \in R^{3}$ is the bias error vector. The scale factor and the misalignment are written in vector form as

$$
\begin{aligned}
& \lambda=\left[\begin{array}{lll}
\lambda_{1} & \lambda_{2} & \lambda_{3}
\end{array}\right]^{\mathrm{T}} \\
& \delta=\left[\begin{array}{llllll}
\delta_{12} & \delta_{13} & \delta_{21} & \delta_{23} & \delta_{31} & \delta_{32}
\end{array}\right]^{\mathrm{T}}
\end{aligned}
$$


In this article, misalignment and bias error of the attitude sensor, usually given as a start tracker, are not assumed because those of the star trackers are usually less than those of the rate sensors.

\section{Unscented Kalman filter}

In this section, the unscented Kalman filter algorithm is presented. Ever since Julier and Uhlmann have proposed the algorithm, numerous modifications and enhancements have been reported. For estimation of parameters as well as state variables two methodologies are mainly employed - joint and dual filtering techniques. Between the two methods, the joint approach is easier and more intuitive to implement. Joint filters augment the original state variables with parameters to be estimated. Since parameters are usually assumed to be constant, time update of the filter model does not change the expanded parameter variables except its process noise if assumed. On the contrary, the dual method set up another filter for parameters so that two filters run sequentially in every step. The state estimator first propagates and updates for given measurements, and then the parameter estimator updates considering the updated output of the state variables as measurements. It is argued that the primary benefit of the dual UKF is being able to prevent erratic behaviour by decoupling the parameter filter from the state filter (VanDyke et al., 2004). However, the UKF in this problem converges only with the joint method as shown later. This section summarizes the UKF algorithm. This summary of the UKF equations follows the descriptions by Wan and van der Merwe (2000) and VanDyke et al. (2004).

\subsection{Joint estimation}

The state variable and the parameter are noted by $s \in R^{n} s$ and $d \in R^{m}$, respectively. The augmented state variable of the joint filter is defined by

$$
\mathrm{x}=\left[\begin{array}{ll}
\mathbf{s}^{\mathrm{T}} & \mathrm{d}^{\mathrm{T}}
\end{array}\right]^{\mathrm{T}}
$$

The filter initialization is conducted with assumed mean and covariance of the augmented state vector.

$$
\begin{aligned}
\hat{\mathrm{x}}\left(\mathrm{t}_{0}\right) & =\mathrm{E}\left\{\hat{\mathrm{x}}_{0}\right\} \\
\mathrm{P}_{\mathrm{x} 0} & =\mathrm{E}\left\{\left(\mathrm{x}\left(\mathrm{t}_{0}\right)-\hat{\mathrm{x}}_{0}\right)\left(\mathrm{x}\left(\mathrm{t}_{0}\right)-\hat{\mathrm{x}}_{0}\right)^{T}\right\}
\end{aligned}
$$

Denoting $\mathrm{L}=\mathrm{n}+\mathrm{m}$, the sigma points of $\mathrm{L}$ are generated using the a priori mean and covariance of the state as

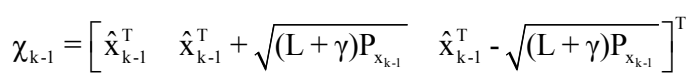

where $\gamma=\alpha^{2}(L+\kappa)$ - L is a scaling parameter. $\alpha$ is usually set to a small positive value. $\mathrm{K}$ is a secondary scaling parameter usually set to 0 . The set of singular points, $\chi_{k}$, is $L \times(2 L+1)$ matrix. Defining $\chi_{i, k}$ as ith column of $\chi_{k}$, each sigma point is propagated through the nonlinear system

$$
\chi_{\mathrm{i}, \mathrm{k} \mid \mathrm{k}-1}=\mathrm{F}\left(\chi_{\mathrm{i}, \mathrm{k}-1}, \mathrm{u}_{\mathrm{k}-1}\right)^{\mathrm{T}}
$$


The posterior mean, $\hat{\mathrm{x}}_{\mathrm{k}}^{-}$, and the covariance, $\mathrm{P}_{\mathrm{xk}}^{-}$, are determined from the statistics of the propagated sigma points as follows:

$$
\begin{aligned}
& \hat{\mathrm{x}}_{\mathrm{k}}^{-}=\sum_{\mathrm{i}=0}^{2 \mathrm{~L}} \mathrm{~W}_{\mathrm{i}}^{\mathrm{m}} \chi_{\mathrm{i}, \mathrm{k} \mid \mathrm{k}-1} \\
& \mathrm{P}_{\mathrm{xk}}^{-}=\sum_{\mathrm{i}=0}^{2 \mathrm{~L}} \mathrm{~W}_{\mathrm{i}}^{\mathrm{c}}\left(\chi_{\mathrm{i}, \mathrm{k} \mid \mathrm{k}-1}-\hat{\mathrm{x}}_{\mathrm{k}}^{-}\right)\left(\chi_{\mathrm{i}, \mathrm{k} \mid \mathrm{k}-1}-\hat{\mathrm{x}}_{\mathrm{k}}^{-}\right)^{\mathrm{T}}+\mathrm{Q}_{\mathrm{xk}}
\end{aligned}
$$

$\mathrm{Q}_{\mathrm{xk}}$ is the process noise covariance of the system. The weights, $\mathrm{W}_{\mathrm{i}}^{\mathrm{m}}$ and $\mathrm{W}_{\mathrm{i}}^{\mathrm{c}}$, are calculated by

$$
\begin{aligned}
\mathrm{W}_{0}^{\mathrm{m}} & =\frac{\gamma}{\mathrm{L}+\gamma} \\
\mathrm{W}_{0}^{\mathrm{c}} & =\frac{\gamma}{\mathrm{L}+\gamma}+1-\alpha^{2}+\beta \\
\mathrm{W}_{\mathrm{i}}^{\mathrm{c}} & =\mathrm{W}_{\mathrm{i}}^{\mathrm{m}}=\frac{1}{2(\mathrm{~L}+\gamma)}, \quad \mathrm{i}=1, \cdots, 2 \mathrm{~L}
\end{aligned}
$$

$\beta$ is used to incorporate prior knowledge. For Gaussian distributions, $\beta=2$ is optimal. The estimated measurement vector $\Upsilon_{\mathrm{i}, \mathrm{k} \mid \mathrm{k}-1}$, ith column of matrix $\Upsilon_{\mathrm{k} \mid \mathrm{k}-1}\left(\in R^{l \times(2 L+1)}\right)$ is calculated by transforming the sigma points using the nonlinear measurement model,

$$
\Upsilon_{\mathrm{i}, \mathrm{k} \mid \mathrm{k}-1}=\mathrm{H}\left(\chi_{\mathrm{i}, \mathrm{k} \mid \mathrm{k}-1}\right)
$$

The mean measurement, $\hat{\mathrm{y}}_{\mathrm{k}}^{-}$, and the measurement covariance, $\mathrm{P}_{\mathrm{ykyk}}$, are calculated based on the statistics of the transformed sigma points.

$$
\begin{aligned}
\hat{y}_{k} & =\sum_{i=0}^{2 L} W_{i}^{m} \Upsilon_{i, k \mid k-1} \\
P_{y k y k} & =\sum_{i=0}^{2 L} W_{i}^{c}\left(\Upsilon_{i, k \mid k-1}-\hat{y}_{k}\right)\left(\Upsilon_{i, k \mid k-1}-\hat{y}_{k}\right)^{T}+R_{y k}
\end{aligned}
$$

$\mathrm{R}_{\mathrm{yk}}$ is the measurement noise covariance matrix. The cross-correlation covariance, $\mathrm{P}_{\mathrm{xkyk}}$, is calculated using

$$
\mathrm{P}_{\mathrm{xkyk}}=\sum_{\mathrm{i}=0}^{2 \mathrm{~L}} \mathrm{~W}_{\mathrm{i}}^{\mathrm{c}}\left(\chi_{\mathrm{i}, \mathrm{k} \mid \mathrm{k}-1}-\hat{\mathrm{x}}_{\mathrm{k}}^{-}\right)\left(\Upsilon_{\mathrm{i}, \mathrm{k} \mid \mathrm{k}-1}-\hat{\mathrm{y}}_{\mathrm{k}}^{-}\right)^{\mathrm{T}}
$$

The Kalman gain matrix is approximated from the cross-correlation and measurement covariances using

$$
\mathrm{K}_{\mathrm{xk}}=\mathrm{P}_{\mathrm{xkyk}} \mathrm{P}_{\mathrm{ykyk}}^{-1}
$$

The measurement update equations used to determine the mean, $\hat{x}_{k}$, and covariance, $P_{x k}$, of the filtered state are 


$$
\begin{aligned}
\hat{\mathrm{x}}_{\mathrm{k}} & =\hat{\mathrm{x}}_{\mathrm{k}}^{-}+\mathrm{K}_{\mathrm{k}}\left(\mathrm{y}_{\mathrm{k}}-\hat{\mathrm{y}}_{\mathrm{k}}^{-}\right) \\
\mathrm{P}_{\mathrm{xk}} & =\mathrm{P}_{\mathrm{xk}}^{-}-\mathrm{K}_{\mathrm{xk}} \mathrm{P}_{\mathrm{ykyk}} \mathrm{K}_{\mathrm{xk}}^{\mathrm{T}}
\end{aligned}
$$

\subsection{Joint UKF state variables}

In this paper, the state vector of the original system consists of the attitude quaternion and the angular rate. The attitude quaternion is a unique non-singular parameterization. However, quaternion has to satisfy unity constraint of the magnitude, which may result in covariance singularity if all the four elements are used. Therefore, only the vector components will be used in the UKF implementation.

Parameters of to be estimated is six components of the moment of inertia, the scale factor error, six elements of misalignment, and the bias of the rate sensor as in Eqs. (10), (12), and (13). Therefore,

$$
x=\left[\begin{array}{llllll}
\delta q_{13}^{T} & \omega^{T} & p^{T} & \lambda^{T} & \delta^{T} & b^{T}
\end{array}\right]^{T}
$$

where

$$
\delta \mathrm{q}=\overline{\mathrm{q}} \otimes \hat{\mathrm{q}}^{-1}
$$

Since the error quaternion is utilized, the state is initialized with

$$
\hat{\mathrm{x}}_{\mathrm{k}-1}=\left[\begin{array}{llllll}
0_{3 \times 1}^{\mathrm{T}} & \omega_{\mathrm{k}-1}^{\mathrm{T}} & \mathrm{p}_{\mathrm{k}-1}^{\mathrm{T}} & \lambda_{\mathrm{k}-1}^{\mathrm{T}} & \delta_{\mathrm{k}-1}^{\mathrm{T}} & \mathrm{b}_{\mathrm{k}-1}^{\mathrm{T}}
\end{array}\right]^{\mathrm{T}}
$$

Once the sigma points are calculated, quaternion component $\delta \mathrm{q}_{13, i}^{\chi}$ is used to obtain the four-element sigma point quaternion $\mathrm{q}_{i}^{\chi}$ to propagate the nonlinear model.

$$
\mathrm{q}_{i}^{\chi}=\left[\delta \mathrm{q}_{13, \mathrm{i}}^{\chi} \quad \sqrt{1-\delta \mathrm{q}_{13, \mathrm{i}}^{\chi} \delta \mathrm{q}_{13, \mathrm{i}}^{\chi}}\right]^{T} \otimes \hat{\mathrm{q}}_{\mathrm{k}-1}
$$

The parameters are assumed to be constant.

$$
\begin{aligned}
\dot{p} & =0 \\
\dot{\lambda} & =0 \\
\dot{\delta} & =0 \\
\dot{b} & =0
\end{aligned}
$$

Now, Eqs. (6), (8) and (29) constitute the nonlinear system model of the UKF. And, lastly the following is the measurement equation.

$$
\begin{aligned}
& \delta \tilde{\mathrm{q}}_{13, \mathrm{k}}=\delta \mathrm{q}_{13, \mathrm{k}}+\mathrm{v}_{\mathrm{qk}} \\
& \tilde{\omega}_{\mathrm{k}}=(\mathrm{I}+\mathrm{M}) \omega_{\mathrm{k}}+\mathrm{b}+\mathrm{v}_{\omega \mathrm{k}}
\end{aligned}
$$

After model propagation, three component of error quaternion is calculated again. After measurement update of Eq. (24), four-element quaternion can be determined using

$$
\hat{\mathrm{q}}_{\mathrm{k}}=\left[\delta \hat{\mathrm{q}}_{13, \mathrm{k}}^{\mathrm{T}} \quad \sqrt{1-\delta \hat{\mathrm{q}}_{13, \mathrm{k}}^{\mathrm{T}} \delta \hat{\mathrm{q}}_{13, \mathrm{k}}}\right]^{\mathrm{T}} \otimes \hat{\mathrm{q}}_{\mathrm{k}-1}
$$


More detailed and helpful discussion on quaternion-based computation can refer (Kraft, 2003).

\section{Numerical simulation results}

In this section, simulation results for hybrid estimation of states, the moment of inertia and the rate sensor calibration will be presented. The joint UKF will be compared to the results using EKF (Myung et al., 2007).

\subsection{Simulation conditions}

In order to estimate the inertia matrix and the gyro calibration parameters, 'persistent excitation' of motion should be guaranteed. A constant body angular velocity vector or one with constant direction will not satisfy this requirement.

As one of the reference trajectories satisfying the 'persistent excitation' condition (Pittelkau, 2001), the following rate trajectory is proposed (Myung et al., 2007).

$$
\omega_{\mathrm{r}}=\phi 1-(1-\cos \phi) 1 \times \dot{1}+\mathrm{i} \sin \phi
$$

where

$$
\begin{gathered}
\phi=50 \pi \mathrm{t}(\mathrm{rad}) \\
\mathrm{l}=\left[\begin{array}{c}
\sin \omega_{1} \mathrm{t} \sin \omega_{2} \mathrm{t} \\
\cos \omega_{1} \mathrm{t} \sin \omega_{2} \mathrm{t} \\
\cos \omega_{2} \mathrm{t}
\end{array}\right] \\
\omega_{1}=0.01 \mathrm{rad} / \mathrm{s} \\
\omega_{2}=0.004 \mathrm{rad} / \mathrm{s}
\end{gathered}
$$

For simulation purposes, a predictive controller (Crassidis et al., 1997) is applied to the spacecraft attitude control. Given reference trajectories to follow, the predictive control synthesizes control command based on nonlinear state prediction strategy using the Taylor series expansion. The reference trajectories are shown in Fig. 1 and Fig. 2.

\subsection{Simulation results}

The following true system and alignment parameters are assumed (Myung et al., 2007):

$$
\begin{aligned}
& J=\left[\begin{array}{ccc}
200 & 50 & -30 \\
50 & 240 & 10 \\
-30 & 10 & 100
\end{array}\right] \mathrm{kgm} / \mathrm{s}^{2} \\
& \lambda=\left[\begin{array}{lll}
5000, & -1000, & -2000
\end{array}\right]^{\mathrm{T}} \mathrm{ppm} \\
& \delta=\left[\begin{array}{lllll}
648, & 1296,972,648, & -648, & 1296
\end{array}\right]^{\mathrm{T}} \text { arcs }
\end{aligned}
$$

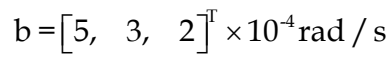




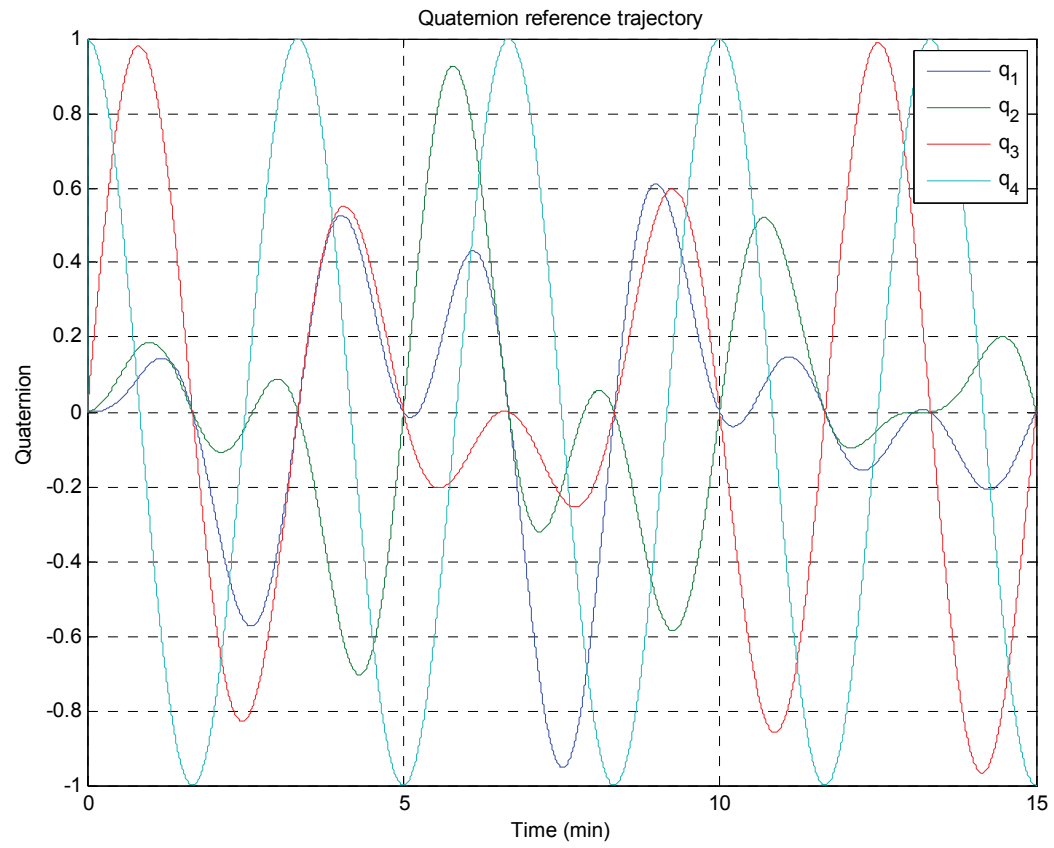

Fig. 1. Quaternion reference trajectory

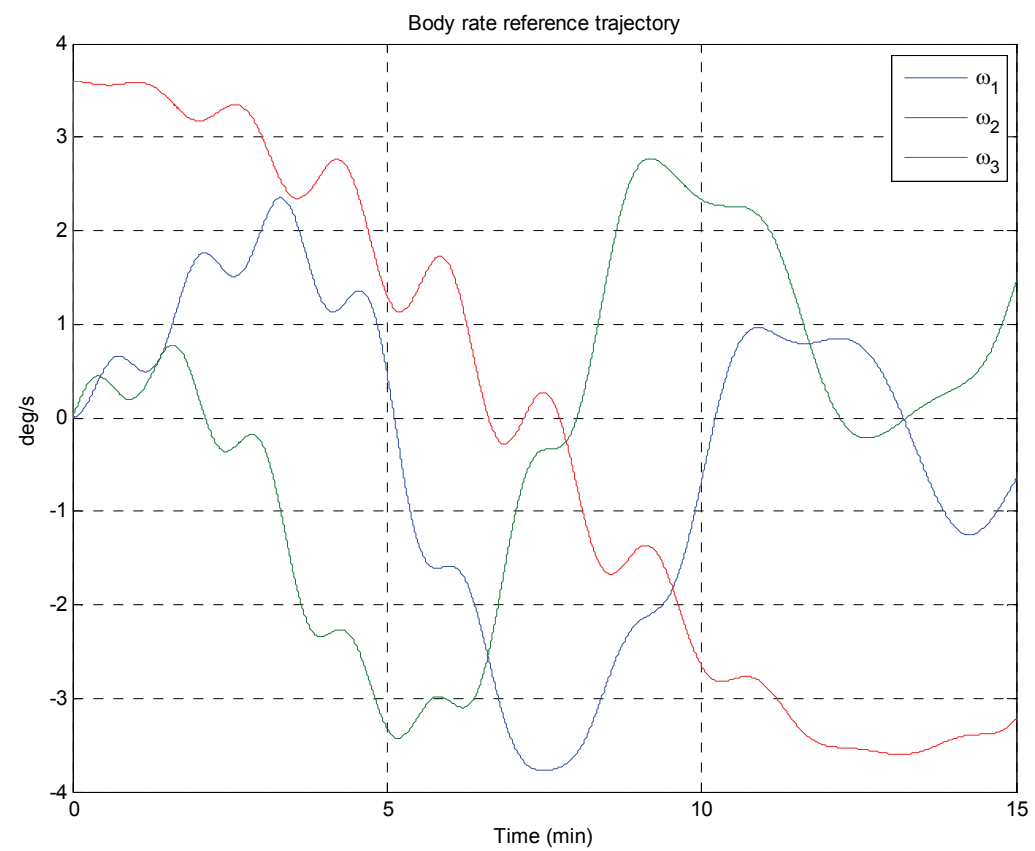

Fig. 2. Body angular rate reference trajectory 
Nominal values of the parameters are given as

$$
\begin{aligned}
& J=\left[\begin{array}{ccc}
160 & 20 & -20 \\
20 & 160 & -20 \\
-20 & -20 & 160
\end{array}\right] \mathrm{kgm} / \mathrm{s}^{2} \\
& \lambda=\left[\begin{array}{lll}
0 & 0 & 0
\end{array}\right]^{\mathrm{T}} \mathrm{ppm} \\
& \delta=\left[\begin{array}{llllll}
0 & 0 & 0 & 0 & 0 & 0
\end{array}\right]^{\mathrm{T}} \operatorname{arcs} \\
& \mathrm{b}=\left[\begin{array}{lll}
0 & 0 & 0
\end{array}\right]^{\mathrm{T}} \mathrm{rad} / \mathrm{s}
\end{aligned}
$$

The process and the measurement noise covariance matrices are designated as

$$
\begin{aligned}
\mathrm{Q} & =10^{-8} \mathrm{I}_{3 \times 3} \mathrm{rad}^{2} / \mathrm{s}^{4} \\
\mathrm{R}_{\mathrm{q}} & =10^{-6} \mathrm{I}_{3 \times 3} \mathrm{rad}^{2} \\
\mathrm{R}_{\omega} & =10^{-5} \mathrm{I}_{3 \times 3} \mathrm{rad}^{2} / \mathrm{s}^{2}
\end{aligned}
$$

Simulation is performed for $15 \mathrm{~min}$. The star tracker and the rate sensor measurements are assumed to be given every $0.2 \mathrm{~s}$. Table $1-4$ present estimation error comparison of the EKF and UKF by Monte-Carlo simulation of 20 runs. The upper data in each cell of the tables are

\begin{tabular}{|c|c|c|c|c|c|c|c|}
\hline & units & $\begin{array}{l}\mathrm{J}_{11} \\
(1 \sigma)\end{array}$ & $\begin{array}{l}\mathrm{J}_{22} \\
(1 \sigma)\end{array}$ & $\begin{array}{l}\mathrm{J}_{33} \\
(1 \sigma)\end{array}$ & $\begin{array}{l}\mathrm{J}_{12} \\
(1 \sigma)\end{array}$ & $\begin{array}{l}\mathrm{J}_{13} \\
(1 \sigma)\end{array}$ & $\begin{array}{l}\mathrm{J}_{23} \\
(1 \sigma)\end{array}$ \\
\hline EKF & $\begin{array}{c}\% \text { error } \\
\%\end{array}$ & $\begin{array}{c}0.140 \\
(0.106)\end{array}$ & $\begin{array}{c}0.163 \\
(0.096)\end{array}$ & $\begin{array}{c}0.527 \\
(0.250)\end{array}$ & $\begin{array}{c}0.137 \\
(0.279)\end{array}$ & $\begin{array}{l}0.319 \\
(0.310)\end{array}$ & $\begin{array}{c}0.548 \\
(0.847)\end{array}$ \\
\hline UKF & $\begin{array}{c}\% \text { error } \\
\%\end{array}$ & $\begin{array}{r}0.080 \\
(0.879)\end{array}$ & $\begin{array}{c}0.073 \\
(0.788)\end{array}$ & $\begin{array}{c}0.185 \\
(1.793)\end{array}$ & $\begin{array}{c}0.072 \\
(0.832)\end{array}$ & $\begin{array}{c}0.023 \\
(1.577)\end{array}$ & $\begin{array}{c}0.063 \\
(4.495)\end{array}$ \\
\hline
\end{tabular}
percentage error with respect to own value. The lower data are normalized values of the final covariances. Therefore, smaller values are more accurate regardless of magnitude of the nominal parameter values. The moment of inertia estimation is very accurate for both EKF and UKF in Table 1. However, rate sensor calibration results of the UKF are much more accurate than those of EKF. If the reference trajectory is designed considering excitation optimality, estimation results will be even more accurate (Sekhavat, 2009).

Table 1. Moment of inertia estimation results of EKF and UKF by Monte-Carlo Simulation

\begin{tabular}{|c|c|c|c|c|}
\hline & units & $\lambda_{1}$ & $\lambda_{2}$ & $\lambda_{3}$ \\
& $(1 \sigma)$ & $(1 \sigma)$ & $(1 \sigma)$ \\
\hline \multirow{2}{*}{ EKF } & $\%$ error & 53.9 & 56.3 & 13.7 \\
& $\%$ & $(82.4)$ & $(205.6)$ & $(117.0)$ \\
\hline \multirow{2}{*}{ UKF } & $\%$ error & 1.17 & 61.8 & 18.8 \\
& $\%$ & $(32.0)$ & $(138.0)$ & $(55.3)$ \\
\hline
\end{tabular}

Table 2. Rate sensor scale factor error estimation results of EKF and UKF by Monte-Carlo Simulation 


\begin{tabular}{|c|c|c|c|c|c|c|c|}
\hline & units & $\delta_{12}$ & $\delta_{13}$ & $\delta_{21}$ & $\delta_{23}$ & $\delta_{31}$ & $\delta_{32}$ \\
& & $(1 \sigma)$ & $(1 \sigma)$ & $(1 \sigma)$ & $(1 \sigma)$ & $(1 \sigma)$ & $(1 \sigma)$ \\
\hline \multirow{2}{*}{ EKF } & $\%$ error & 91.2 & 121.9 & 72.0 & 103.8 & 59.6 & 14.0 \\
& $\%$ & $(87.1)$ & $(47.6)$ & $(75.0)$ & $(72.9)$ & $(85.0)$ & $(64.1)$ \\
\hline \multirow{2}{*}{ UKF } & $\%$ error & 28.3 & 6.81 & 13.5 & 7.74 & 6.51 & 10.9 \\
& $\%$ & $(49.3)$ & $(18.3)$ & $(32.9)$ & $(34.3)$ & $(46.2)$ & $(26.9)$ \\
\hline
\end{tabular}

Table 3. Rate sensor misalignment estimation results of EKF and UKF by Monte-Carlo Simulation

\begin{tabular}{|c|c|c|c|c|}
\hline & units & $\mathrm{b}_{1}$ & $\mathrm{~b}_{2}$ & $\mathrm{~b}_{3}$ \\
& $(1 \sigma)$ & $(1 \sigma)$ & $(1 \sigma)$ \\
\hline \multirow{2}{*}{ EKF } & $\%$ error & 267.1 & 166.1 & 37.7 \\
& $\%$ & $(29.6)$ & $(47.6)$ & $(67.9)$ \\
\hline \multirow{2}{*}{ UKF } & $\%$ error & 2.46 & 11.6 & 1.93 \\
& $\%$ & $(9.63)$ & $(16.0)$ & $(23.8)$ \\
\hline
\end{tabular}

Table 4. Rate sensor bias estimation results of EKF and UKF by Monte-Carlo Simulation

Fig. 3 to Fig. 10 illustrates one of the UKF simulation results with time. Each variable has different convergence time constant. The attitude and the rate converge very fast as in Fig. 3 and Fig. 4. And then the moment of inertia components converge. And finally calibration parameters converge.
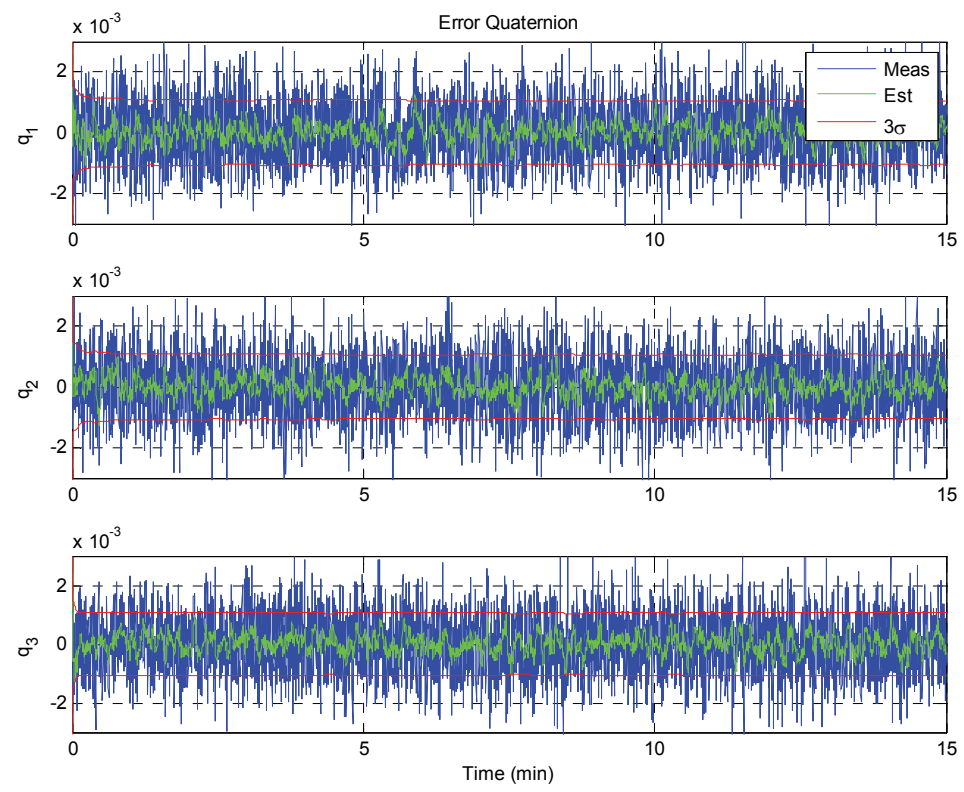

Fig. 3. Attitude estimation error with $3 \sigma$ bounds 

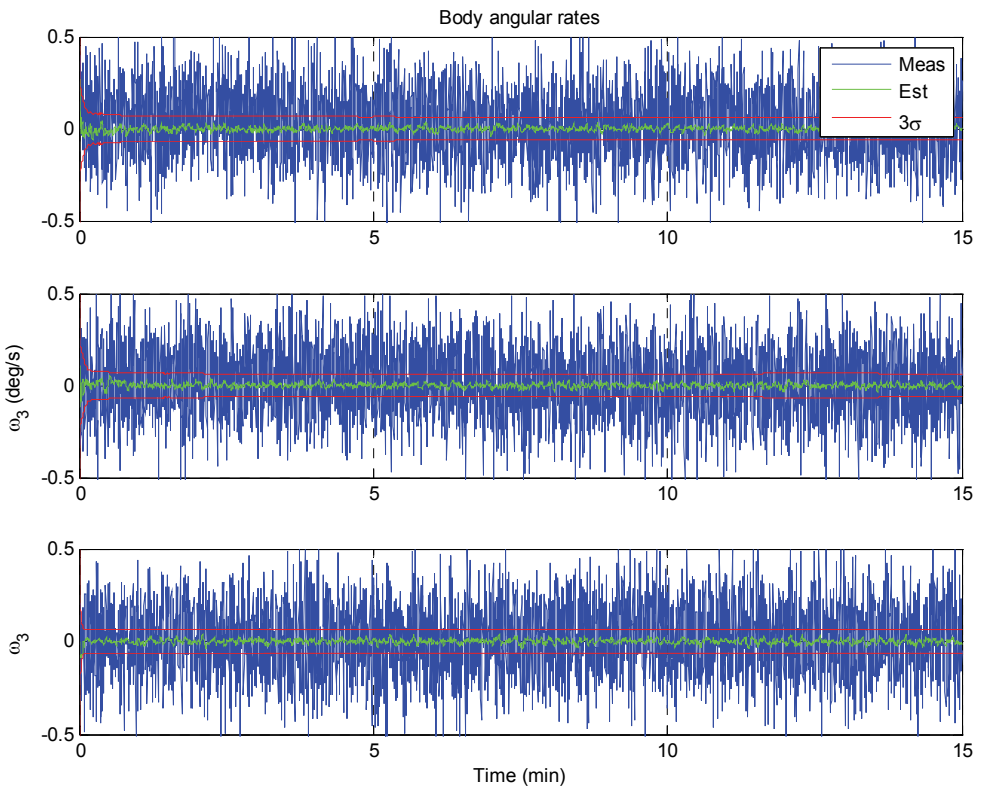

Fig. 4. Angular velocity estimation error with $3 \sigma$ bounds

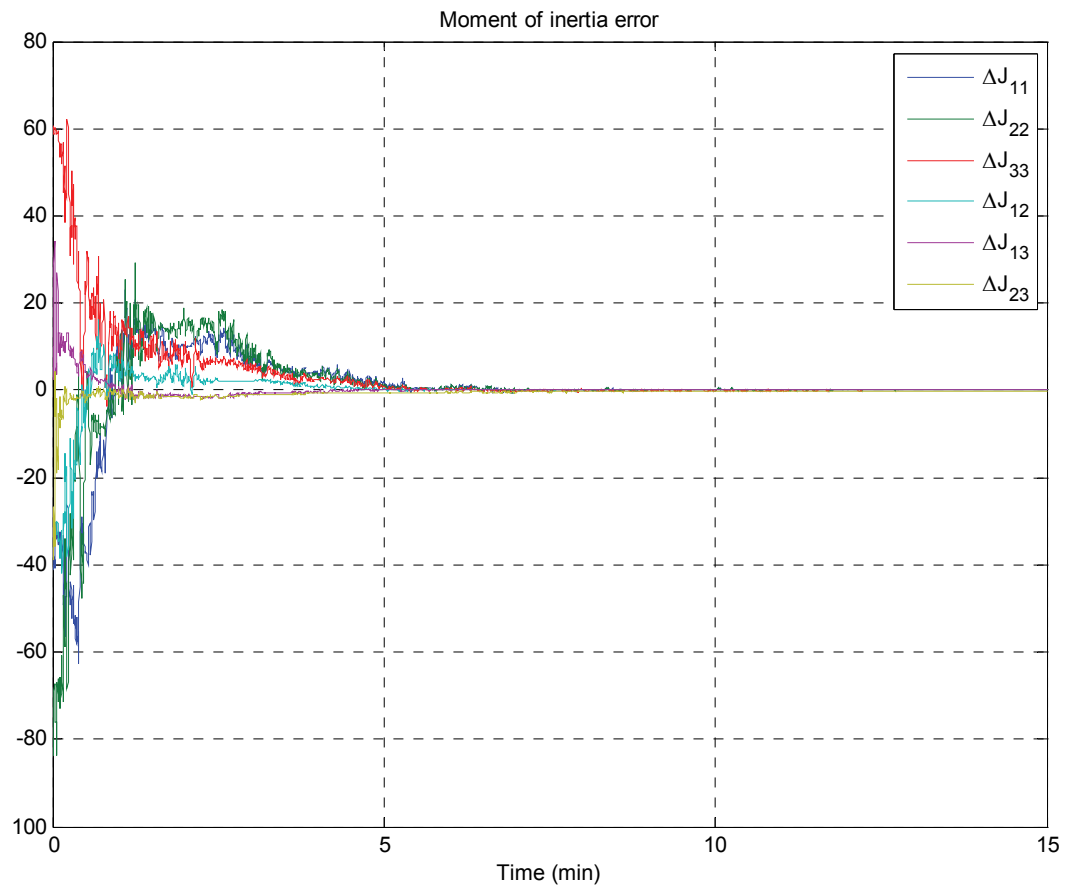

Fig. 5. Moment of inertia estimation error 

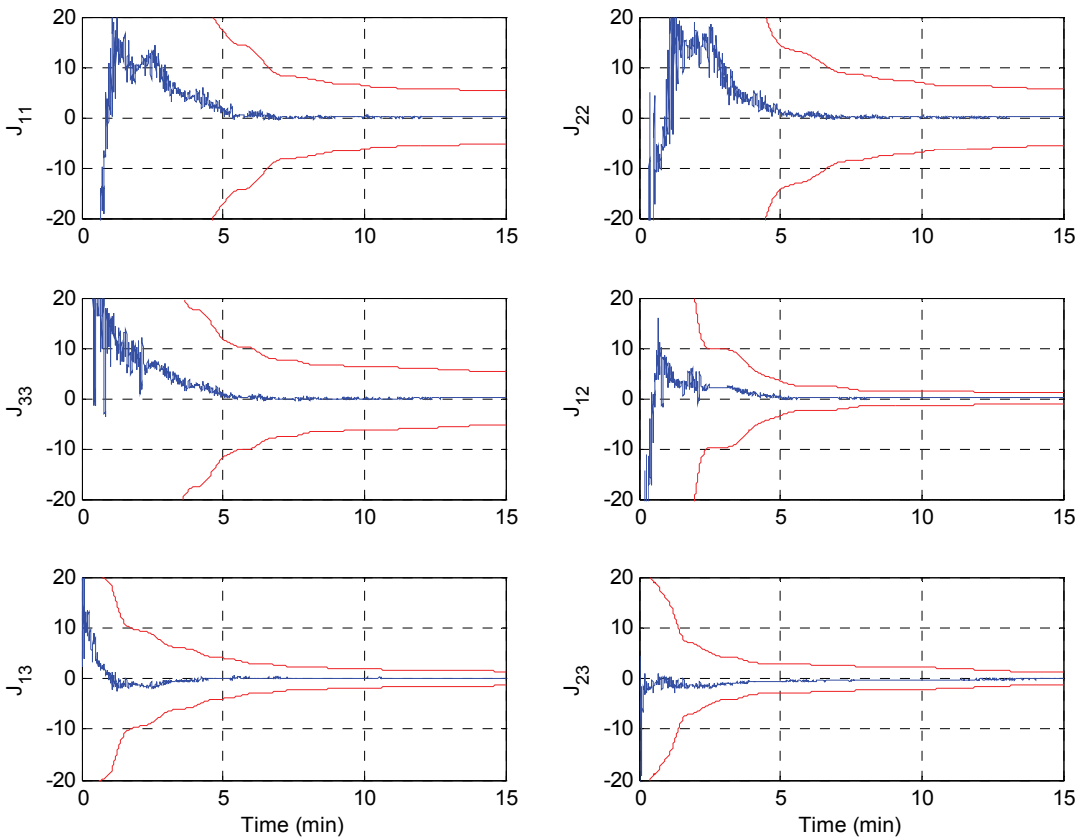

Fig. 6. Moment of inertia estimation error with $3 \sigma$ bounds
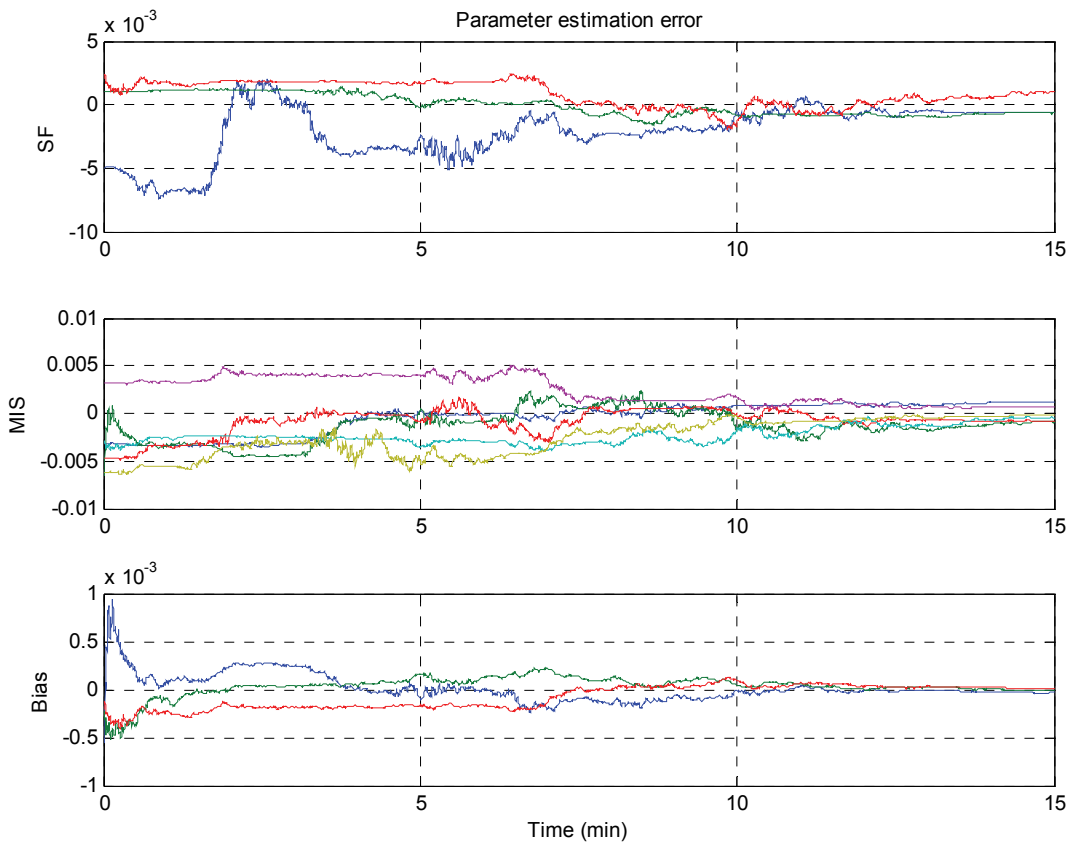

Fig. 7. Rate sensor calibration error 

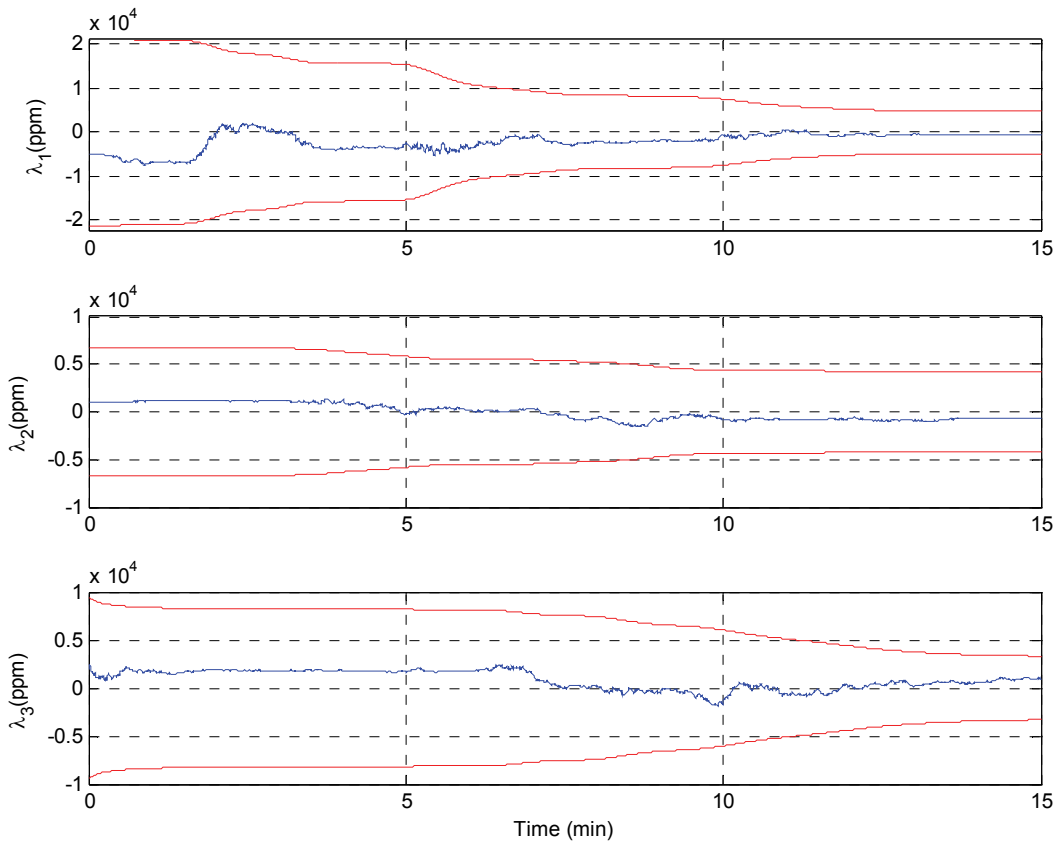

Fig. 8. Rate gyro scale factor estimation error with $3 \sigma$ bounds
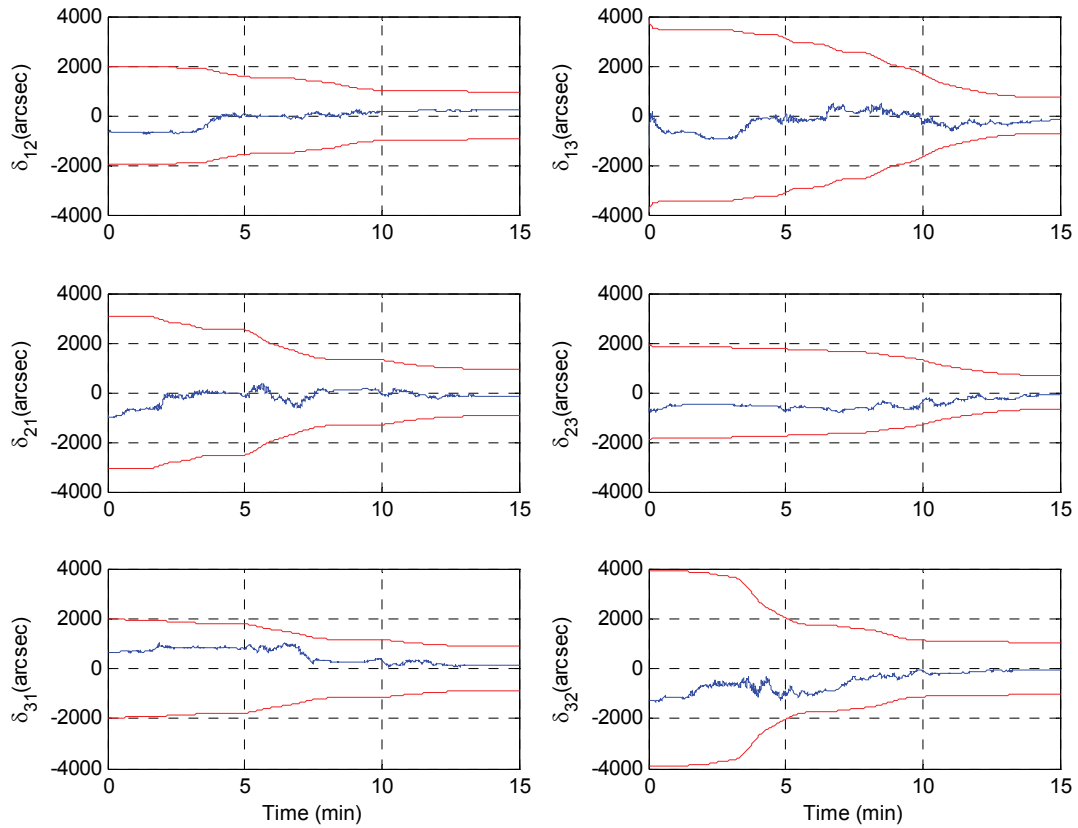

Fig. 9. Rate gyro misalignment estimation error with $3 \sigma$ bounds 

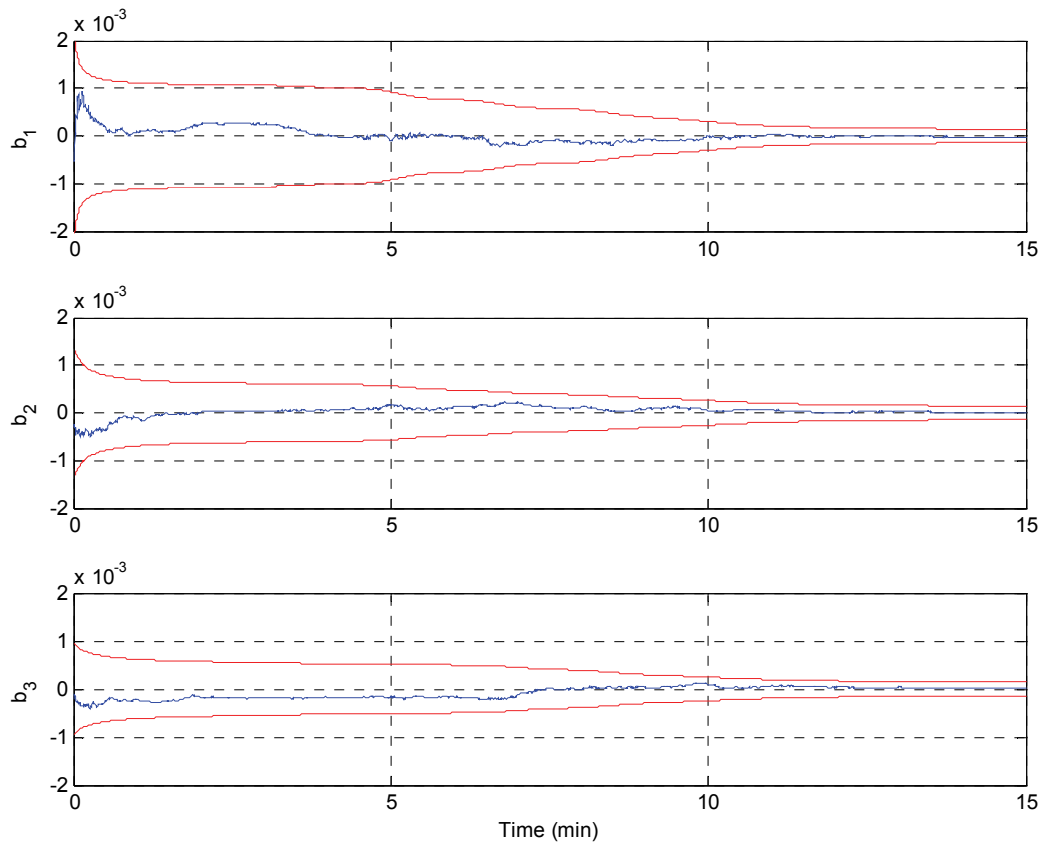

Fig. 10. Rate gyro bias estimation error with $3 \sigma$ bounds

\section{Conclusions}

This study presented hybrid estimation of the moment of inertia of spacecraft and calibration parameters of the rate sensor such as the scale factor error, six elements of misalignment and the gyro bias error during a single estimation maneuver. For this purpose, a joint unscented Kalman filter (UKF) algorithm was successfully applied and the performance was compared to the results using the extended Kalman filter (EKF). While the components of the moment of inertia were estimated very accurately by both the EKF and the UKF, the rate sensor calibration parameters - scale factor, misalignment, and bias error were filtered much better by the UKF than the EKF. Simulation results demonstrated applicability and performance for spacecraft system identification and the gyro calibration simultaneously.

This concept of estimation procedure can reduce efforts and costs for periodic parameter estimation and gyro calibration of spacecraft in-orbit. Also, proposed method can be extended to calibration maneuvers of other equipments such as star trackers and optical payloads.

\section{References}

Ahmed, J.; Coppola, V. T. \& Bernstein, D. S. (1998). Adaptive asymptotic tracking of spacecraft attitude motion with inertia matrix identification, Journal of Guidance, Control and Dynamics, Vol. 21, No. 5, pp. 684-691 
Bordany, R. E.; Steyn, W. H. \& Crawford, M. (2000). In-orbit estimation of the inertia matrix and thruster parameters of UoSat-12, Proceedings of the 14th AIAA/USU Conference on Small Satellites, Logan, Utah, USA, August 2000

Crassidis, J. L.; Markley, F. L., Anthony, T. C. \& Andrews, S. F. (1997). Nonlinear predictive control of spacecraft, Journal of Guidance, Control and Dynamics, Vol. 20, No. 6, pp. 1096-1103

Crassidis, J. L.; Markley, F. L. \& Cheng, Y. (2007). Survey of nonlinear attitude estimation methods, Journal of Guidance, Control and Dynamics, Vol. 30, No. 1, pp. 12-28

Creamer, G.; DeLaHunt, P., Gates, S. \& Leyenson, M. (1996). Attitude determination and control of Clementine during lunar mapping, Journal of Guidance, Control and Dynamics, Vol. 19, No. 3, pp. 505-511

Julier, S. J. \& Uhlmann, J. K. (1997). A new extension of the kalman filter to nonlinear systems, Proceedings of the SPIE AeroSense International Symposium on Aerospace/Defence Sensing, Simulation and Controls, Orlando, Florida, USA, April 1997

Kalman, R. E. (1960). A new approach to linear filtering and prediction problems, Transactions of the ASME-Journal of Basic Engineering, D, Vol. 82, pp. 35-45

Kraft, E. (2003). A quaternion-based uscented Kalman filter for orientation tracking, Proceedings of IEEE 6th Coference of Information Fusion, pp. 47-54

Lai, K. L.; Crassidis, J. L. \& Harman, R. R. (2003). In-space spacecraft alignment calibration using the unscented filter, Proceedings of AIAA Guidance, Navigation, and Control Conference Exhibit, Austin, Texas, USA, August 2003

Ma, G. -F. \& Jiang, X. -Y. (2005). Unscented Kalman filter for spacecraft attitude estimation and calibration using magnetometer measurements, Proceedings of the 4th International Conference on Machine Learning and Cybernatics, Guanzhou, August 2005

Myung, H.; Yong, K. -L. \& Bang, H. (2007). Hybrid estimation of spacecraft attitude dynamics and rate sensor alignment parameters, Proceedings of International Conference on Control, Automation and Systems, Seoul, Korea, October 2007

Myung, H. \& Bang, H. (2008). Spacecraft parameter estimation by using predictive filter algorithm, Proceedings of IFAC World Congress, Seoul, Korea, July 2008

Pittelkau, M. E. (2001). Kalman filtering for spacecraft system alignment calibration, Journal of Guidance, Control and Dynamics, Vol. 24, No. 6, pp. 1187-1195

Pittelkau, M. E. (2002), Everything is relative in spacecraft system alignment calibration, Journal of Spacecraft and Rockets, Vol. 39, No. 3, pp. 460-466

Sekhavat, P. ; Karpenko, M. \& Ross, I. M. (2009). UKF-based spacecraft parameter estimation using optimal excitation, AIAA Guidance, Navigation, and Control Conference, Chicago, Illinois, USA, August 2009

Van der Merwe, R. \& Wan, E. A. (2001). The squre-root unscented Kalman filter for state and parameter-estimation, Proceedings of IEEE International Conference on Acoustics, Speech, and Signal Processing, Vol. 6, pp. 3461-3464

VanDyke, M. C.; Schwartz, J. L. \& Hall, C. D. (2004). Unscented Kalman filtering for spacecraft attitude state and parameter estimation, Advances in the Astronautical Sciences, Vol. 118, No. 1, pp. 217-228 
Wan, E. A. \& van der Merwe, R. (2000). The unscented Kalman filter for nonlinear estimation, Proceedings of IEEE Symposium 2000 (AS-SPCC), Lake Louise, Alberta, Canada, October 2000

Wertz, J. R. (Ed.) (1978). Spacecraft Attitude Determination and Control, pp. 414-416, Kluwer 


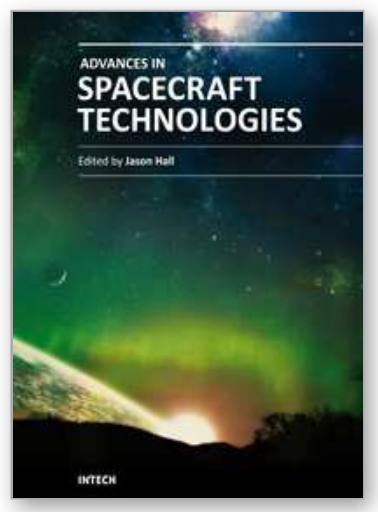

\author{
Advances in Spacecraft Technologies \\ Edited by Dr Jason Hall
}

ISBN 978-953-307-551-8

Hard cover, 596 pages

Publisher InTech

Published online 14, February, 2011

Published in print edition February, 2011

The development and launch of the first artificial satellite Sputnik more than five decades ago propelled both the scientific and engineering communities to new heights as they worked together to develop novel solutions to the challenges of spacecraft system design. This symbiotic relationship has brought significant technological advances that have enabled the design of systems that can withstand the rigors of space while providing valuable space-based services. With its 26 chapters divided into three sections, this book brings together critical contributions from renowned international researchers to provide an outstanding survey of recent advances in spacecraft technologies. The first section includes nine chapters that focus on innovative hardware technologies while the next section is comprised of seven chapters that center on cutting-edge state estimation techniques. The final section contains eleven chapters that present a series of novel control methods for spacecraft orbit and attitude control.

\title{
How to reference
}

In order to correctly reference this scholarly work, feel free to copy and paste the following:

Hyun-Sam Myung, Ki-Lyuk Yong and Hyo-Choong Bang (2011). Unscented Kalman Filtering for Hybrid Estimation of Spacecraft Attitude Dynamics and Rate Sensor Alignment, Advances in Spacecraft Technologies, Dr Jason Hall (Ed.), ISBN: 978-953-307-551-8, InTech, Available from:

http://www.intechopen.com/books/advances-in-spacecraft-technologies/unscented-kalman-filtering-for-hybridestimation-of-spacecraft-attitude-dynamics-and-rate-sensor-ali

\section{INTECH}

open science | open minds

\section{InTech Europe}

University Campus STeP Ri

Slavka Krautzeka 83/A

51000 Rijeka, Croatia

Phone: +385 (51) 770447

Fax: +385 (51) 686166

www.intechopen.com

\section{InTech China}

Unit 405, Office Block, Hotel Equatorial Shanghai

No.65, Yan An Road (West), Shanghai, 200040, China

中国上海市延安西路65号上海国际贵都大饭店办公楼 405 单元

Phone: +86-21-62489820

Fax: $+86-21-62489821$ 
(C) 2011 The Author(s). Licensee IntechOpen. This chapter is distributed under the terms of the Creative Commons Attribution-NonCommercialShareAlike-3.0 License, which permits use, distribution and reproduction for non-commercial purposes, provided the original is properly cited and derivative works building on this content are distributed under the same license. 